\title{
Proceed with Care: Reimagining Home IoT Through a Care Perspective
}

\author{
Cayla Key \\ School of Design, Northumbria University, Newcastle \\ upon Tyne, UK \\ c.key@northumbria.ac.uk \\ Nick Taylor \\ School of Design, Northumbria University, Newcastle \\ upon Tyne, UK \\ n.taylor@northumbria.ac.uk
}

\author{
Fiona Browne \\ Retired History Teacher, Dundee, UK
}

\begin{abstract}
As the internet is increasingly embedded in the everyday things in our homes, we notice a need for greater focus on the role care plays in those relationships-and therefore an opportunity to realize unseen potential in reimagining home Internet of Things (IoT). In this paper we report on our inquiry of home dwellers' relationships to caring for their everyday things and homes (referred to as thingcare). Findings from our design ethnography reveal four thematic qualities of their relationships to thingcare: Care Spectacle, Care Liminality, Ontological Braiding, and Care Condition. Using these themes as touchstones, we co-speculated to produce four speculative IoT concepts to explore what care as a design ethic might look like for IoT and reflect on nascent opportunities and challenges for domestic IoT design. We conclude by considering structures of power and privilege embedded within care practices that critically open new design imaginaries for IoT.
\end{abstract}

\section{CCS CONCEPTS}

- Human-centered computing; • Human computer interaction (HCI);

\section{KEYWORDS}

Internet of things, home, design ethnography, research-throughdesign, care, care ethics, things, smart home

\section{ACM Reference Format:}

Cayla Key, Fiona Browne, Nick Taylor, and Jon Rogers. 2021. Proceed with Care: Reimagining Home IoT Through a Care Perspective. In CHI Conference on Human Factors in Computing Systems (CHI '21), May 0813, 2021, Yokohama, Japan. ACM, New York, NY, USA, 15 pages. https: //doi.org/10.1145/3411764.3445602

\section{INTRODUCTION}

"Why home? Home is where people are made and undone" [76:xii]. As the opening line to Sarah Pink's book on design and ethnography

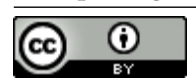

This work is licensed under a Creative Commons Attribution International 4.0 License.

CHI '21, May 08-13, 2021, Yokohama, Japan

(c) 2021 Copyright held by the owner/author(s).

ACM ISBN 978-1-4503-8096-6/21/05.

https://doi.org/10.1145/3411764.3445602

\author{
Jon Rogers \\ School of Design, Northumbria University, Newcastle \\ upon Tyne, UK \\ jon.rogers@northumbria.ac.uk
}

Making Homes, this makes sense as we increasingly understand home to be a complex entanglement of social, political, environmental, personal, and technological forces that converge in mundane ways on an everyday basis. However, we choose to focus on what 'things' other than people are made and undone at home. Built on the back of long-standing concepts such as ubiquitous and ambient computing (e.g., $[16,79,85])$, we attend to the particular concerns of domestic IoT when placed within those entanglements. As sales of these devices grow, their promise of enhancing our everyday experiences through values such as efficiency, productivity, security, and entertainment remain static. These products and services do not encompass the full or even partial range of values that are made and undone within a home. Home is a dynamic and lively space of boredom, imagination, secrecy, power, and more. Critically, for this paper, home is a place where care is enacted, received, complicated, and profoundly felt when missing. Perhaps now more than ever as networked technologies are no longer optional upgrades but are what enable us to work, connect with family, educate ourselves and our children, even participate in democracy, we have a tacit sense of the importance of care in our individual conceptions of home.

To address these broader complexities, design in HCI has long focused on domestic spaces (e.g., [1, 18]), diversifying notions of home itself as well as living situations (e.g., [15, 25, 46, 65, 66, 90]) and on social relations and mediations within (e.g., [3, 13, 27]). Domestic IoT has become of increased interest for HCI researchers in an attempt to reflect values beyond those offered by commercial interests such as the passing of heirlooms [63], upcycling practices [88], or religious practices [89], to name a few. Yet we observe a need for greater focus on care and therefore an opportunity to realize unseen potential in using care as a lens to reimagine home IoT.

Why a care perspective? According to care ethicist Maria Puig de la Bellacasa "for interdependent beings in more than human entanglements, there has to be some form of care going on somewhere in the substrate of their world for living to be possible" [9:5]. In other words, any new IoT brought into a home will be cared for, in one way or another, by one thing or another. Yet this very basic idea is contrary to dominant visions of 'smart' home technologies which suggest a lack of work, attention, negotiation, and embodied knowledge needed to make them fit-the home is simply computationally 'smart' enough to do all of that on its own. We add to other voices 
of dissent by arguing that the byproduct of a 'frictionless' technology is one which obscures all of the care labor needed to make it fit. These products attempt to assert a coherent ecosystem in an incoherent space; it is no surprise, then, that care is a fundamental and ongoing means of negotiating fitness in these complex spaces. Although care and care ethics per se has only had a limited presence in HCI discourse (e.g., [42, 53, 80, 81]), they are robustly developed in feminist theory where relationality, reciprocity, and vulnerability are central values. We argue that these values, when applied to domestic IoT, open up novel ways to design and consider the impacts of such technologies on homeworlds. Furthermore, as calls for a more trustworthy, fair, open, and inclusive IoT (e.g., [21, 32, 52]) echo across knowledge domains we argue that care as a design perspective is one generative response to those calls. Our work takes to heart and attends to the specificity of anthropologist Shannon Mattern's provocation: 'if we apply 'care' as a framework of analysis and imagination for the practitioners who design our material world, the policymakers who regulate it, and the citizens who participate in its democratic platforms, we might succeed in building more equitable and responsible systems" [58].

In this paper we present our inquiry of home dwellers' relationships to caring for their everyday things and homes which we will hence refer to as thingcare. Using an auto-dialogical researchthrough-design (RtD) approach (described in more detail in a later section) we conducted a six-month design ethnography with one participant (we will refer to as Browne) and one researcher (the first author Key), then co-speculated to produce a set of four speculative IoT concepts to investigate the question: what might care as a design consideration look like for home IoT? First, we present the four themes which describe qualities of care relationships to everyday things. We will then showcase the provocative concepts generated to translate those qualities to home IoT and discuss design implications therein. Our contributions are: (1) introducing notions of a care ethics for things to design and HCI discussions of home IoT; (2) detailed ethnographic accounts that look at care enactments to expand the way we understand home as an assemblage of interdependent things; (3) speculations into what care might look like as a design material that open up provocations, opportunities, and frictions.

\section{CARE AS A FEMINIST ETHIC}

Care ethics can be understood as a feminist moral theory that privileges relationality, reciprocity, responsiveness, and particular (vs generalized) selves and others when confronting the implications of care labor and caring relations [39]. Care ethics presupposes a living practice and embodied understanding rather than moral obligation or normative judgment based on universalized principles and abstract reasoning, as in other ethics. Although originally aimed at disrupting power structures in politics and epistemology (e.g., $[35,62,82])$ which disadvantage on the basis of sex and gender, care ethicists have engaged care across a multitude of relationalities, concerns, and domains (e.g., [20, 26, 51]) throughout its history. This productive broadening is exemplified by Berenice Fisher and Joan Tronto's general yet rich definition of care as "a species activity that includes everything that we do to maintain, continue, and repair our 'world' so that we can live in it as well as possible. That world includes our bodies, our selves, and our environment, all of which we seek to interweave in a complex, life-sustaining web" [29:40]. In attending to the labor of maintaining these worlds, care ethics is careful not to romanticize care, cautioning "against the conflation of care with affection, happiness, attachment, and positive feelings" [60:719] in part through highlighting the ways in which care work is often rendered invisible. Because care is a cumulative effort of attentiveness and resilience it is easily overlooked [57], making it "ripe for exploitation and co-optation" [40:7]. It has been argued that "care first is a political commitment" [10:7], however because it places relationality at its core, its effects reverberate throughout interpersonal relationships and everyday hierarchies with moral consequence.

The politics and ethics of care have been effectively positioned to investigate the technology-mediated social spaces and communities of concern to design and HCI. Shaowen Bardzell critiques the Heterogeneous Home [1] (and by extension, smart home design visions more generally), by applying both a justice ethics and care ethics perspective to the project, thus teasing out its normative political and moral principles and their "regressive sociological consequences" [7:768] (i.e., indifference and exploitation of less privileged or legitimized humans). In addition to using care ethics as a tool for critique, HCI scholars have used care to understand the complexities of various relationships such as those between researchers and participants (e.g., [81]) or intercommunity relationships such as hacker collectives (e.g., [80]). For example, Balaam et al. [6] communicate the often-unacknowledged emotional work needed as researchers of Experience Centered Design-sharing care ethics' commitment towards the unseen labor of care. In their reflections on participatory design, Light and Akama use feminist notions of care to focus on the interdependences of researchers and participants [53] yet highlight how care "extends intricately into the wider structures of production and consumption, living and dwelling with" [53:153]. Indeed, it is in the 'living and dwelling with' where this paper seeks to contribute.

While most research in this realm focuses on care ethics within and around human relationships, feminist STS scholar Puig de la Bellacasa maintains that "care is relational per se" [10:69] and in a deep reading of Fisher and Tronto's definition (quoted earlier) argues: "it speaks of care as a manifold range of doings needed to create, hold together, and sustain life and continue its diverseness. This also means that an understanding of human agencies as immersed in worlds made of heterogeneous but interdependent forms and processes of life and matter, to or not to care about/for something/somebody, inevitably does and undoes relation" [10:70]. For Puig de la Bellacasa, care's relational core extends to all things (i.e., more-than-human) which participate in care as defined by Fisher and Tronto. In this light, we can easily see how caring for the interdependent things at home is an essential practice of making and undoing those relationships.

Lastly, we recognize that although not explicitly about notions of care, other scholars in feminist HCI have contributed work that this paper endeavors to build on. Shaowen Bardzell critiques a critical strategy feminism often takes and emphasizes "the potential for feminism to contribute to an action-based design agenda" [8:3]. Although we have seen care productively used as an analytical tool in the examples above, we also imagine care as a preemptive design consideration which might resist unstated yet dominant value sets 
in favor of diverse, or at least explicit ones. Bardzell shares care ethic's relational conviction when she urges designers to practice awareness of the widest possible ecology of stakeholders and to attend to the concomitant effects of their designs.

\section{RELATIONSHIPS WITH THINGS}

As we have seen, care extends far beyond interpersonal connections to encompass a multitude of relationships across ecologies. This section tends to some broader philosophies and specific practices with things which mirror or share affinity with our understanding of care as a way to relate to things.

HCI researchers have adopted many tactics when trying to tackle something as banal yet slippery and immense as everyday human-thing-interaction. We are not the first to look towards noncomputational domestic stuffs to inform new designs and technologies (e.g., $[19,47,50,78])$. Most germane to practices of care is the genre of HCI concerned with cultures of repair and maintenance (e.g., [43-45, 54, 68, 72]), which explore the social, political, and material negotiations of repair work (e.g., [69]), how repair and care can challenge hierarchical human-object narratives (e.g., [48]), and how repair can creatively do and underdo (e.g., [54]). Tsaknaki et al. [83] propose using three principles of Wabi-Sabi: 'nothing lasts,' 'nothing is finished,' and 'nothing is perfect' as starting points for what we would consider to be more caring relationships. Houston et al. look to fixer collectives to understand values in repair culture as ongoing and contingent [41]. They argue that valuation is " $a$ course that includes the forms of maintenance and repair by which objects are continually sustained and kept live... [which] forge new relations" [41:1412]. Rosner et al. introduce the notion of 'material traces' as a way to account for "the dynamic and evocative nature of form" [70:1649]. Through their investigation of traces, the authors articulate "nuanced particularities of form" and "inextricably linked relationships through which materials come into being, pointing to the contingencies between people, environments, and substances" [ibid]. We agree with the evocative power and generative openings offered by material traces and see them as part of the same constellation of material engagement focused on noticing and relationality across multiple worlds.

In summary, the examples above demonstrate that care has always been silently implicated in how we seek to understand relationships to things both theoretically and practically-with environmental, ethical, political, ontological, and epistemological implications sympathetic to existing concerns within HCI and design. By bringing specific attention to the nuances of care in these realms we join Mol et al. in hoping that "such articulation work may help to make the specificities of care practices travel. Perhaps, when articulated, when put in so many words, care will be easier to defend in the public spaces where it is currently at risk of being squeezed" [59:10].

\section{OUR APPROACH: AUTO-DIALOGICAL RESEARCH THROUGH DESIGN}

This research was set against the challenges of the COVID-19 pandemic, which precluded methods requiring visits to participants' homes or other in-person methods. However, this also presented an opportunity to recommit to feminist scholars' calls for alternative ways of knowing and designing through collaborative, communal, and relational practices that recognize partial perspectives and value situated experiences across diverse expertise [28, 55]. Our approach of auto-dialogical RtD is a collaborative approach where a researcher and participant engage in tandem design ethnographies (in our case journaling and mapping), analyze and synthesize their fieldwork, and engage in making as a means of knowledge generation.

This approach is inspired by the discursive quality of duoethnography [77], the focus on making as a means of thinking in autobiographical design [61], and the participatory envisioning of co-speculation [4]. Duoethnography views the experiences and narratives of two or more researchers as a "valuable site of knowledge production, interrogated power relations, and positioned knowledge formation as an intersubjective and relational process" [17:5], thus resisting universal and disembodied knowledge claims that are "from everywhere and so nowhere" [37:590]. Autobiographical design, similarly, privileges the first-person experience of an individual who is the researcher, designer, and genuine user of an artifact or system [61]. Finally, co-speculation is based on the principles of co-design [75] and speculative design [4] in which "the recruiting and participation of study participants who are well positioned to actively and knowingly speculate with us in our inquiry in ways that we cannot alone" [86:94].

In short, Browne and Key used critical journaling to document everyday enactments of care. In tandem with this fieldwork, they used critical mapping to collaboratively draw out inprogress themes and co-speculated on a series of imaginary IoT concepts to explore the design implications of their ethnographic findings.

\subsection{Contextual Background: Pilot Work}

As noted, this study was interrupted by the COVID-19 global pandemic. As a result, early efforts were retroactively treated as pilot work and were central in motivating and informing the development of the method described above. During the pilot work, Key visited three households (recruited from University and personal networks) for a two-hour home visit [76] where she conducted semi-structured interviews, collaborated in a Thing Interview [14], and left the home dwellers with a lightweight cultural probe [33]. Data from these visits in the form of audio transcripts, photographs, and returned probe materials were not formally analyzed but were reviewed for inspiration.

\subsection{Working with Browne}

Documenting thingcare can be an intimate and often illusive proposition (as we will see in the case of a 20 -year care practice that went unnoticed) and explorations of the costs of care require vulnerability. In developing this approach, we recognized the need for care and attention not just in the research topic but in the participant/researcher relationship as well. Browne is a retired history teacher, self-proclaimed feminist, and avid gardener who lives with her husband and dog (now that their two grown children have moved out) in the house they built 36 years ago in Scotland. Browne was one of the participants in the pilot research with whom Key had developed an immediate rapport. 

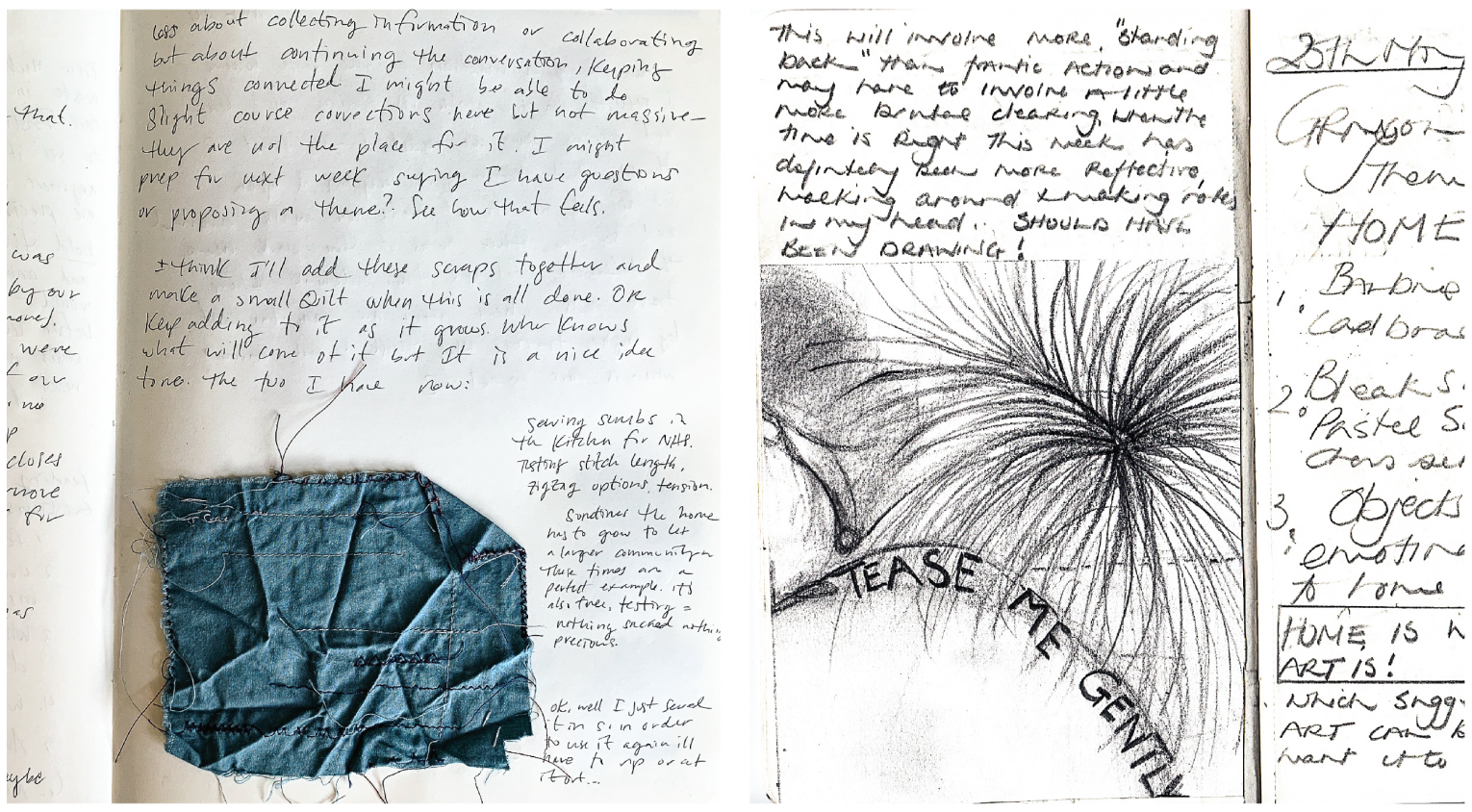

Figure 1: A critical journal entry from Key (left), and from Browne (right).

Although Key had developed a basic structure for engagement before approaching her, Browne's voice was instrumental in shaping the approach to fit their collective needs, interests, and capacities. During the six-month study, Browne and Key held weekly calls to discuss, debrief and to connect as collaborators and developing friends, and have exchanged over 75 emails to fluidly exchange ideas and reflections in parallel to other documentation methods as well as discuss logistics. As Browne liked to remind (or perhaps reassure) Key "I am not doing anything different, I am just looking and thinking more, and this has given me a great chance to do it, so it really is a gift."

\subsection{Documentation}

Browne and Key adapted critical journaling and overview mapping [73] to document everyday acts of care enacted or witnessed in each of their homes. These approaches emphasize "chronologically capturing contextual research, self and peer critique, and regular 'overview maps' alongside the iterative design processes" [73:4]. By scaffolding 'reflection on action' as well as 'reflection for action' [73], current thinking is more formally incorporated into the next iteration, allowing layers of knowing and doing to continue folding in on themselves. Translating these documentation methods to their unique practices was productive in framing enactments of thingcare as 'doings' (a term Browne championed and which she and Key thought felt right), rather than more reductive or prescriptive terms they explored in their initial meeting such as making, assembling, restoring, curating, playing, repairing, displaying, crafting, or remixing.

4.3.1 Critical Journaling. Both Browne and Key kept journals (Fig. 1) where they documented their care 'doings' using a simple what, why, how, and reflect protocol. For each entry, they asked themselves to describe and/or sketch their actions, the motivation for their actions, and their methods. As prompts for reflection, they asked themselves: how did doing this change the way you see the thing? How did it change the way you see home? How did it feel while doing it (were you feeling focused, idle, meditative, imaginary, creative, etc.)? They used photographs as enhancements to these entries, which captured details that were difficult to describe and aided in their discussions, and acted as placeholders to remind them to come back and write an entry after the fact.

4.3.2 Critical Mapping. To structure loose synthesis as they proceeded (i.e., reflection for action), Browne and Key conducted two critical mapping sessions where they individually and collaboratively mapped their doings (Fig. 2), looking for connections, tensions, and themes across multiple and open axes such as place, temporality, material, implication, and other relations. They used those individual maps as a starting point when they met to share, question, explore, stitch, and unstitch their experiences and ideas as a collective endeavor, again focusing on open axes of connection and tension. According to Sadokierski, "regularly pulling back to 'map the big picture'...helps maintain perspective 'in action' and captures the evolution of a project for later reflection" [73:4]. These collective mapping sessions took place via Zoom and lasted approximately two hours.

\subsection{Analysis}

Although forms of analysis and synthesis were taking place collaboratively throughout the study (as seen in Figure 2), a third and formal round of thematic analysis was conducted by Key in dialogue with Browne. Key used open and axial coding from the myriad data sources (journals, photographs, emails, phone 


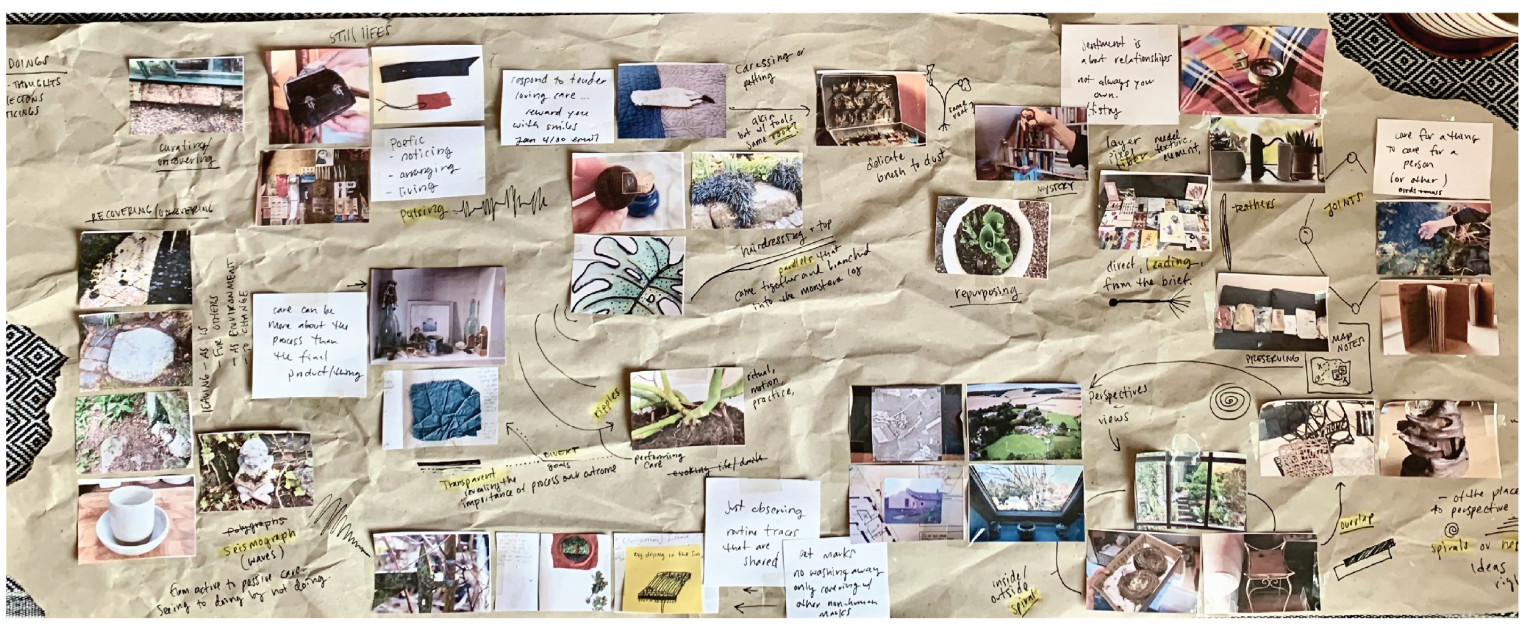

Figure 2: A critical map constructed and annotated by Key during a session with Browne.

transcripts, zoom recordings, notes, and critical maps) to surface and organize themes around qualities of thingcare and her and Browne's relationships to the processes of thingcare (the 'doing'). After generating a set of coherent themes, Key and Browne met via zoom to discuss them as well as Key's early post-it note sketches. They discussed each item's lineage in the themes they developed during their collective mapping, new or broader implications, and if Browne thought the sketches represented these themes and her and Key's work up to that point.

\subsection{Catalog of Spectacular Things}

Inspired by Khovanskaya et al.'s generative blending of sketching for "productive resistance" [49:5381] alongside ethnographic fieldwork, Key began sketching ideas for speculative IoT devices, relationships, and paradigms in parallel to the analysis detailed above. She used the process of iterative sketching as a way to embody, make concrete and tangible the themes emerging from the analysis which helped her deepen the themes and keep them closely grounded in her and Browne's experiences. Early sketches also provided a generative and approachable 'in' when co-speculating on these more abstract themes and ideas with Browne who referred to them as "an out of body nudge into the future." With Browne's feedback, Key iterated and refined four sketches to reflect each theme's possible implications for future IoT. These concepts were collectively titled Catalogue of Spectacular Things (inspired by [30]).

Browne and Key's process of iteration-analysis-iteration naturally led to them being close to the data. While we see this is a strength of the approach, they felt a need for even more 'productive resistance.' To that end, Key suggested they share the concepts with some of the other participants from the pilot work. Using concept decks for participant feedback is an established practice in HCI across diverse practices such as cultural probes, design workbooks, zines, and more (e.g., [24, 31, 33, 34]). The finalized Catalogue of Spectacular Things was then presented back to Browne as well as five individuals from the pilot study in the form of simple animated
GIF's with audio vignettes from the perspective of the thing (see supplementary materials for all four animations with voiceovers).

Responses to the Catalogue of Spectacular Things affected on multiple levels: firstly, they revealed further insights into the themes themselves, and secondly, they bridged Key and Browne's auto-dialogical fieldwork (which was not limited to but ended up primarily focusing on non-connected things) to the world of IoT-opening up space to respond to the research question: what might care as a design consideration for IoT look like?

\section{QUALITIES OF THINGCARE}

Here we present four themes that explore the emergent qualities of Browne and Key's relationships to caring for the things of their homes. These themes describe Browne's and Key's relationships to care as they relate to foreground aspects such as tactility and ambivalence, but also to unseen or background aspects such as cost, interdependence, and inaction. We will share the speculative concepts developed which embody these themes and refract, amplify, and trouble notions of care for home IoT.

\subsection{Care Spectacle: From Intention to Attention}

Through their auto-dialogical approach, Browne and Key were able to focus not just on the end results of care but the experiential qualities of the process as a whole. This theme explores what care looks and feels like in the moment, how things can grab one's attention and lure them into experiencing them as active and lively things, and when care is a process rather than an outcome. In these instances, care was conceptualized not as a concern or an intention to "act" but as a means of giving and getting attention, revealing performative aspects of thingcare.

5.1.1 Tactility. Acts of care can be idealized for their noble intent or emotional meaning; however, Browne and Key found instances in which the physical enactment of care in itself felt sensuous and satisfying. For example, Browne has developed several rituals around the reuse and reappropriation of leftover bits of things from 
everyday living. In one instance she discussed how she saves the used paper napkins from lunch every day, puts her orange peels inside, folds each corner over and tucks them in to make a nice little bundle. These get stored in the sunroom for about a month to fully dry out before being used as fire starters that fill the house with the smell of orange and smoke. When contrasting these to a similar practice of making fire starters from leftover bits of candle bundled up in newspaper she explains, "they are folded in a different way, but I get weird satisfaction from making them and using them."

Both Key and Browne noticed something similar when tending to their plants. Key had observed her monstera plant was looking a bit dull and decided to dust the leaves to allow more light to penetrate. She began by using a duster but found that ineffective so then tried a rag dipped in warm water. This made the process slower and required her to hold each individual leaf in one hand and stroke with the other. She described the experience to Browne saying, "doing it felt beautiful. . almost like a dance." This account reminded Browne of a journal entry she had made earlier in the week about removing the dead fronds from one of her potted grasses. She described the activity as "hairdressing" saying that as she walks by it is as if the grasses call to her: "sort my hair out. It's been blowing in the wind! Just to put your hands through it, it's a wonderful feeling. It is irresistible!" These examples highlight how the tactility of maintenance work elevated them to be noticed as enactments of care, ones which were reciprocal (almost romantically so) and where care was in the process more than the outcome.

5.1.2 Shimmer. Anthropologist Deborah Bird Rose, who has been learning from "Aboriginal people in the Victoria River region of Australia's Northern Territory" [84:51] for over 30 years describes shimmer as "an Aboriginal aesthetic that helps call us into these multispecies worlds" [84:53]. This particular aesthetic (used "in terms of lures that both entice one's attention and offer rewards"), she argues, "allows you, or brings you, into the experience of being part of a vibrant and vibrating world" [ibid]. In this vein, Browne and Key experienced how care, enacted as a practice of noticing as well as doing, could animate the vibrancy of things. One way they experienced this most profoundly was through what Browne calls their "little living compositions all around the house." They came to see unintended still lifes in assemblages of things as banal as Key's cutting block where her salt grinder and water pitcher sit, or Browne's pile of contorted hazel branches sitting in a wheelbarrow. When describing the process of noticing these still lifes, Browne remarked, "I go about my business doing things and I cannot but stand back and look at it as a work of art, as it were. Like your plants or my plants or the stones. So, this has given me a great chance to do it."

In these cases, caring for the composition manifested as an openness to be lured in by its 'shimmer.' However, that openness operated in waves, pulses, ebbs, and flows. During one of the critical mapping sessions, Browne described this phenomenon as "look at me moments, [where] the still life says, 'look at me'... then, a lot of times, it's just quiet." In these moments, care drew them in to stop, see, and appreciate more fully; other times, however, they were compelled to assemble or reassemble things in ways that helped them define a sense of space, but that also uplifted the liveliness of that thing, adding to a sense of its space. Key described this as

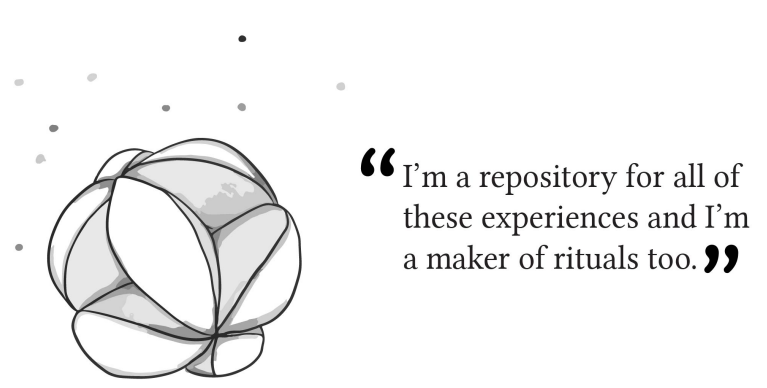

Figure 3: Secure Sensations image and quote from the audio vignette

"making something look like something in its own right," referring to the way she keeps her embroidery needle laced through a ribbon and placed in a wooden bowl on her desk.

The examples above illustrate some performative aspects of care when encountering everyday things. They recount experiences with care through nuances of touch and look rather than intention and outcome. We saw how acts of maintenance and reuse were made enjoyable, special, and even ritualistic through tactile engagement, and how being open to noticing the mundane shimmer all around made their worlds livelier. As Key and Browne agree: "sometimes it's about the outcome, but a lot of the time it's just about the doing of it." And yet these are not hedonistic dalliances. Although they might have felt pleasure, the point was not to be pleased; indeed, it was to care. As succinctly stated by Key when discussing this with Browne, "it's not about what, but how we care."

5.1.3 Speculative Concept: Secure Sensations. To embody this theme and explore its design implications we developed the concept Secure Sensations (Fig. 3), a touch-based password manager that generates unique passwords based on the texture and feel of different home items. A smart camera's password might be the slightly ticklish yet soothing feeling of the shag rug between your toes. A smart fridge's password could be the feeling of powdered snow falling on your eyelashes. This concept turns password management (something otherwise unremarkable in its mundanity) into a unique and enlivening experience through tactile engagement and experiential shimmer.

When discussing this concept with Browne she called it "a place which encourages you to look, to touch, to think, and to remember. In turn the secret sensation prompts you to act." Her response unknowingly bears resemblance to Jane Bennet's 'sensuous enchantments' which, she claims, can move one from endorsing to practicing values and ethics [12]. For Browne, an added benefit of engaging with the spectacle of Secure Sensations is its encouragement to act on the value of password security.

When showing this concept to participants from the pilot study yet another dimension was revealed. Participant Amelia remarked, "I can also see that it might get a bit irritating after a while, and that an experience you chose at a particular time might be something you don't necessarily want to repeat all the time." Her response speaks to the emotional cost of attentiveness and suggests such experiences 
might lose their shimmer if experienced too often. In contrast, Terry felt like it would be too alluring, stating, "on the whole, I think it would be distracting. There is such a thing as being too far off in your own head." These responses echo Rose's warning that "for shimmer to capture the eye, there must be absence of shimmer" [84:54] while also extending it to tactile and emotional attentiveness.

5.1.4 Implications for IoT: Or how can home loT be more like a dried-up pile of orange peels? Care ethics takes as its starting point an appreciation that care is a practice of embodied dependence. According to Puig de la Bellacasa, "caring is more than an affectiveethical state: it involves material engagement in labours to sustain interdependent worlds" [9:198]. This section illustrates how engagement with aesthetic and performative aspects of that practice or process can open up lifeworlds by bringing into focus their lively relation, materiality, and dependency. What would happen if IoT took such an appreciation as its starting place? Might we begin to envision new ways of leveraging aesthetic and somaesthetic experiences and openly design for such shifts in perspective?

Although home IoT are themselves lively effecting things, current instantiations make it difficult to noticeably perceive their relational effects [23], fueling "the image of dead or thoroughly instrumentalized matter [which] feeds human hubris and our earthdestroying fantasies of conquest and consumption" [12:ix]. Dominant visions (we use the term both literally and figuratively) of IoT are at once thoroughly predictable yet utterly opaque. In contrast, Browne's engagement with her orange peels, for example, was beautifully surprising yet transparent and immediately perceivable as lively. Using the orange peels as fragrant fire starters was completely unintended. Yet, the knowledge that leaving them in the sun would dry them out, that a napkin would hold them together but still be appropriate to burn, at what point they would be done curing, and, in this case, the satisfying labor needed to make this all happen was transparent (enough) to her. Browne had an emergent and embodied understanding of what else the orange peels could be when remixed in a new set of relations-opening up opportunities to riff, adapt, and imagine other outcomes with those relations. Recalling that "care constitutes a feeling with, rather than a feeling for, others. When mobilized, it offers visceral, material, and emotional heft to acts of preservation that span a breadth of localities: selves, communities, and social worlds" [40:2], we can imagine how designing from a lens of Care Spectacle might cultivate feelings with rather than for lively home IoT and their entanglements. How might that experientially (or viscerally) change the way we live with, maintain, enable or impede the persistence of those entanglements (i.e., practicing values in addition to endorsing them)?

\subsection{Care Liminality: Tensions at World Boundaries}

In this theme we describe the tensions which arose when Browne and Key brought things into their worlds and cared to make them fit. Care did not always result in Browne and Key feeling in harmony with their things, but instead unresolved or destabilized things, revealing their unfinished quality, laying bare obfuscated acts of care and care labor, and opening up dialogues with things and environments.
5.2.1 Unfinished and Transitional. Throughout this study, Browne and Key encountered enactments of care which were not discrete events or singular instances, but instead were ways of being with things in a transitional space which was held and never resolved. For example, when Browne was describing how a newly rediscovered box of buttons would make the perfect addition to the chair that she has been renovating for over 20 years, Key remarked on how comfortable Browne was with the chair's never finished yet always 'right' quality, saying, "if you cared about it you would finish it, would be the narrative there, but we both know that's not the truth." Browne's rejoinder took this idea further, rhetorically asking, "what would finished even look like? Will I do it, will I not, it doesn't bloody matter." Through this example we see how Browne's long-term care for her chair is not about fixing or stabilizing it. She did not bring the rickety old chair in to restore it with frenzy to make it seamlessly fit in. Rather, appreciating and embracing the chair within and throughout its many transformational states was how she cared.

Although embracing transformational states and appreciating unfinishedness can alleviate some of the burden of care (restoring with frenzy sounds exhausting indeed) it can also obfuscate what care labor is exerted. In fact, this conversation about the chair was not something Browne had documented in her journal or added to the critical maps. She did not immediately recognize that she was describing a 20-year practice of care. This prompted Key to reflect on hidden long-term care in her home and admit that, even given her research interests, "I am surprised at what still doesn't jump out at me as caring."

5.2.2 Ambivalence. When bringing things into homeworlds, Browne and Key also encountered moments where caring to find fitness entailed an implicit shift away from utility and functionality alone and opened dialogues or negotiations with materiality, environment, and agency on how that better fit might be achieved. Browne and Key first discussed this in relation to Browne's interest in collecting, and sometimes augmenting, discarded bird's nests. She described the tension she felt between wanting to be creative with them but also feeling unsettled by saying, "well, as you know, I have quite a few nests, quite a lot of nests, and I've made some into. . . framed them and added the threads and whatever in them. Then, that also seemed a little bit like spoiling them by making them some kind of thing they really weren't, although I tried for it not to be like that." Browne took care when deciding what to add to a nest, using things like gold thread to mimic the bits of hair which she found woven in already. Her husband Dallas explained, "my mum used to comb her hair and throw it out the window because she had long hair. There was a tree below, and we found this dove's nest in it, and it was woven with her hair." In cases like this, care is ambivalent when bringing together worlds. Care existed in her negotiations with additive materiality, (i.e., using fine thread as opposed to, say, glitter), but also with how that reflection unsettled her, when she chooses not to add material, and her respect for the ways in which her world and that of the dove had already been co-existing.

In addition to negotiating with additive materials, Browne and Key struggled to negotiate with other agentic forces when tasks aimed at preservation destabilized the delicate fit previously achieved. In one instance, Key noticed a beloved piece of driftwood 


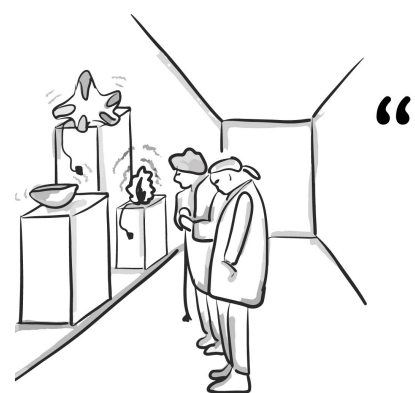

S6 There just simply isn't enough homes for every device that gets left behind in this world. 98

Figure 4: Care4Tech image and quote from the audio vignette

was feeling brittle. In an attempt to preserve it, she rehydrated the wood with oil. Although this had the effects of strengthening the wood, it also darkened it and in effect "put it back in the water." It no longer looked or felt right to her. She explained, "I made it look like I had just found it, but it was supposed to be indoors, and it was supposed to have dried up over time. So, there's, sort of, trying to straddle these two things and trying to make it fit." Again, care in this example cuts in two directions. Care was in her initial desire to preserve the driftwood, but also in her desire not to erase the material traces of her actions (e.g., removing it from the river), the environment (e.g., her cold Scottish home), its own agencies (e.g., porosity). When reflecting on this and other similar occurrences, Key laments, "we put them too much into their own worlds."

We have demonstrated that tension exists within and as a result of care enactments when fitness between worlds is at stake. However, these notions also reposition care away from an authoritative figure with the power to fix, finish, or stabilize. Caring then is relocated towards negotiations with a multitude of agents across worlds.

5.2.3 Speculative Concept: Care4Tech. To respond to the quality of liminality we present the concept Care4Tech (Fig. 4), a shelter and adoption service for home IoT. In a world where every home has smart devices that are custom-crafted for that unique environment, this service arose to care for unwanted or orphaned things. Some are still young and moldable; others have been around a while with more established 'programing'-Care4Tech tries to find homes for them all. This concept flips current ideas of mass produced IoT around as a way to explicate design implications when the unique worlds of homes, inhabitants, and devices collide and IoT are forced to negotiate fitness in a new space.

Browne responded to this concept with the rhetorical question, "is this not what we all do?" Because for her, "there is always a place for a new 'thing' to enhance an existing still life or group of objects giving your heart another lift." Browne's responses focused on the effect a new assemblage would have on herself, her practice of creatively reassembling discarded things, and what she considered to be the obvious thing to do. In contrast, participant Kathy homed in on how this would affect the existing things in her home, saying, "routine maintenance would be automatic. Overall items would have a longer life span due to regular, preventative care." In Kathy's mind, these technologies would care for themselves and care for each other through more explicitly cooperative relationships.

While the two responses above speak to forms of potential harmony, tensons were also exposed. For example, Amelia's reaction revealed an implicit hierarchy of care: "it makes the tech devices seem more important, and more 'human,' somehow. I think things like plants, books, textiles and ceramics are important and I take care of them but have not thought about tech in this way." Similarly, Browne likened the concept to an authoritative body, noting, "museums can also do this by acknowledging the worth, the history and the interest in discarded objects."

5.2.4 Implications for IoT: Or how can home loT be more like a rickety old chair? Although care ethics is concerned with questions of morality, because it privileges relationality and responsiveness it entails "a specific modality of handling questions to do with the good" [59:13] rather than prescribing what is 'good' universally. Indeed, according to Mol et al., in care ethics "it is taken as inevitable that different 'goods', reflecting not only different values but also involving different ways of ordering reality, have to be dealt with together" [ibid]. This section exposes modalities and temporalities of negotiations that seek to compromise across a plurality of worlds and (at times competing) 'goods.' How might we reimagine home IoT if we designed with a broader and more fluid notion of what is 'good'? Would home IoT begin to design for the 'good' of things and worlds historically considered less deserving of care?

Although it is an uncomfortable burden, home IoT design is already reifying normative ideas about what is 'good' through its processes and outcomes [7]. One such notion of 'good' we see pervade current visions of home IoT is that of efficiency. Almost an anathema to this notion is Browne's relationship with her chair renovation. Not only is Browne approaching her relationship to her chair in the slowest way possible, evaluating its efficiency is entirely impossible without an ideal finished state. Using counter frames such as slowness (e.g., $[36,64]$ ) has been one generative way to challenge notions of efficiency in HCI design. Yet even in these productive efforts, other normative 'goods' (e.g., self-reflection or extended interaction) continue to seep in through their blind spots. When using a care perspective, however, we can see Browne's relationship with her chair as both a challenge to this dominant IoT 'good' while also being attentive to how different temporalities affect actual and perceived care labor. By designing with Care Liminality, might we challenge notions not just of what is 'good' but also when? When using a design frame that centers relationality, might we knowingly be able to design at the intersection of labor and temporality (as well as many other competing, complementarity, and shifting 'goods')?

\subsection{Ontological Braiding: Binding and Leaking}

This theme concerns the ways in which noticing, attuning to, and affecting things through care influence what it means to be oneself and what it means to be those things. In framing this theme, we look outside of our own (US and UK) cultural traditions to nonwestern ways of thinking and borrow the notion of 'ontological braiding' from anthropologist Anne Salmond (further detailed by [2]), who describes it as a Māori phenomenon where one's "place in the relational field and modes of being are mutually implicated" 
[74:301]. Salmond describes this as an unconflicted "process of juxtaposition and exchange [with] generative effects. It makes it possible to deal creatively with competing and shifting universalisms without feeling the need for an 'eye of God' account in which only one set of propositions about reality can prevail" [ibid]. Here, we extend this notion to juxtapositions and exchanges with things as a result of care enactments.

5.3.1 Deep Witnessing. When practicing care, Browne and Key often felt a heightened awareness of those things that, in their everydayness, seemed inconsequential yet at times were experienced as vital. In one example, Key had been documenting little working-from-home hacks (clothes pins to keep together papers, stitching notes into her journal, using a desk plant as a webcam privacy screen etc.). She had initially shared this collection with her studio and only months later thought of putting this in her journal to share with Browne. She reflected on the time gap saying, "caring is doing and noticing, not necessarily in that order." During their next phone conversation, Browne and Key discussed this in more detail, talking through the difference (if any) between doing and noticing, between looking and seeing. Browne argues that "noticing is everything. Not doing but noticing, noticing the little details, noticing the intricacies, noticing the connections, noticing what things are and who they are."

When discussing specific examples such as a journal entry where Key explains how caring for her plants "does make them seem more alive. . they are usually so passive but during the dusting you see them, and they show how they are not so passive" the implications are made concrete. This example evokes a closer kinship to witnessing rather than looking, seeing, or noticing. Bearing witness carries an implication that something exists; that it is true-so here we see how care is a means to witness modes of being. Upon further reflection Browne extends the thinking to suggest, "what you see is who you are?" to which Key offers, "or how you see is who you are?" These unresolved questions imply the exchange, though exactly what was exchanged might allude description, the sense of change is salient.

5.3.2 Flows. While care sometimes took on a reflexive 'doing' (witnessing) in addition to directed action (e.g., cleaning) Browne and Key also experienced times where inaction was a means to realize care. Browne and Key share a love for outdoor spaces, and both enjoy tending to the various plants within and around their homes. However, according to Browne, "sometimes one shouldn't do anything at all to look after things." As an example, she described a set of wicker chairs left in the garden to be picked at by the hens, bleached by the sun, and infested with bugs. She explained, "I think I probably leave things to deteriorate more than I restore them, frankly. I would be inclined to look at them, and see them deteriorate, and look at that process and be interested by that." In this example, Browne's interest in tuning-in to the flows of the hens, sun, and bugs felt more nurturing to her home than placing them inside and away from the elements.

Key related to this attunement through a recent experience in her neighborhood park (a large open field with small clusters of trees speckled throughout). Key and her son walk the park every morning and she considers it an extension of their home. One morning she recalls in her journal, "because of the rain we are off the main path... that changes the micro ecosystem and when we

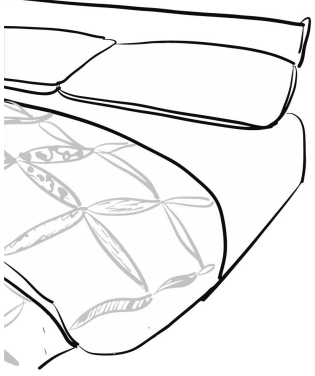

66 I'm not the same blanket as I was yesterday and I guess who is? I just wear my heart on my sleeve a bit more maybe. 98

Figure 5: Sensitive Snuggler image and quote from the audio vignette

are forced to take refuge under their branches to keep out of the rain, we are pushed into these spaces and we experience them differently." The rain physically moved Key into experiencing the flows and paces of the grasses, oozing moss and lichen, bark, etc. in a way that she wouldn't normally when sticking to the neatly mowed inner field. She also reflected on how that different mode of being affected her sense of home, saying, "you feel like a visitor in one scenario and you feel like an owner in the other." This example shows that when care manifests as attunement it can (at least temporarily) shift hierarchical modes such as 'owner' and 'visitor.'

Lastly, instances also occurred when care manifested in letting (as in not resisting) things attune to Browne and Key as in when a beloved wedding cup of Key's broke. In her journal Key explained, "you'd think for something so meaningful I would be devastated to see it 'break'... but I think some things that matter need to move with life." The cup was not broken beyond repair; the crack was minute yet repairing the cup (even skillfully or artfully) did not feel like an act of care in this case. Recalling the notion of 'material traces' mentioned earlier, Key's care was in preserving that trace-not erasing the cup's material linkage to its 'people, environments, and substances' [71]. That erasure would have feet like a locking out rather than inviting into their contingent relationship.

The effects of care on our modes of being are relational; they work in both directions. In some instances, the experience of deeply witnessing revealed agencies in people and things. Other times, attuning to other flows and paces helped actualize care in moments where inaction felt more nurturing, redrawing notions of power, and troubling ideas of ownership and stewardship.

5.3.3 Speculative Concept: Sensitive Snuggler. The Sensitive Snuggler (Fig. 5) is a smart blanket sensitive to all the goings-on of the house where it lives. The physical, emotional, and social changes around it are woven into its fabric-its texture an ever-evolving representation of its environment. A cat's death, an uncanny dream, a seasonal flowering plant, job insecurity, new wallpaper-all are made visible (if incomprehensible) on its surface. This concept practices a form of deep witnessing on the entire home. Through attuning to the bugs, plants, and dust it both reflets its surroundings and co-creates it.

Interestingly, Browne felt like this concept was a microcosm of what a "true home" should be-i.e., a reflection, and stated that, "an 
animal, a plant, a found object should be comfortably and carefully housed in order to belong." In contrast, however, Amelia responded, "we are maybe used to living with pets which do this, and this is one of the pluses of having a pet, but the idea that more objects could do this is unsettling." Browne's response reveals a quixotic equation of infinite attention to model homeliness, yet Amelia's comment reminds us of the emotional cost not only of giving care and consideration but also of the burden of constant and numerous points of reflection.

Although some were troubled by the idea, this concept felt familiar as many participants mentioned a likeness to people or pets in their responses. For example, Terry remarked, "I had to laugh when I was listening. The script reminds me of someone I know, and don't particularly like, so NO, I don't think I could have nor would I want a Sensitive Snuggler in my home. Too much, 'I' $m$ so special' of an attitude." Terry found the Snuggler's position of privilege off-putting. Browne too felt the Snuggler was special but framed it as a welcome opportunity for caring interaction and communication. She explains, "this reminds me of conversations about Stevie the cat who was always with us. On the bed, the sofa in the kitchen, the garden, listening, watching, communicating always. Like a cat, the Snuggler cannot / should not be put in the cupboard. It should be seen touched and stroked and listened to. . . just like a cat."

5.3.4 Implications for IoT: Or how can home IoT be more like a soggy walk in the park? As we have stated earlier, care ethics is oriented towards a particular self and a 'concrete other' whereas other forms of ethics seek to position an unindividuated self into moral judgment against a 'generalized other' (meaning the class, gender, history, etc. of each individual is irrelevant). For individuals in a care ethics framing, "neither are they acting for the sake of all others or humanity in general; they seek instead to preserve or promote an actual human relation between themselves and particular others" [39:23]. Of equal importance (and particularly thorny when focused on relationships with things) is finding ways to give those 'others' a voice. As philosopher Seyla Benhabib explains, "neither the concreteness nor the otherness of the 'concrete other' can be known in the absence of the voice of the other... we tend to constitute the otherness of the other by projection and fantasy or ignore it in indifference" [11:168]. In this section we explore the ways in which thingcare (as acts of noticing and attuning), in part, gave voice to and revealed some of those particulars-affecting not only the relation but the individuals. What might happen if home IoT were designed with more of a 'voice' of their own, relating their own histories, hierarchies, materiality, etc.? If home IoT were rougher and less closed off, would we find it easier to effect moral decisions upon them and ourselves in relation to them-and in turn the oppressive or exploitative systems of their creation or use?

Although there have been cases of high-profile outrage at the misuse of home IoT (e.g., [67]), by and large the moral issues surrounding these technologies are too subtle and diffuse to always resonate as personal everyday erosions and erasures. In contrast, Key's experience in her local park was very personal and the experience made her question her own complicity in a system which has bred notions of land ownership so deeply that her individual conception of home included a public park where the lives and homes of countless other species are daily threatened as humans flock to its sunny slopes and destructively 'maintain' its non-native turf. When designing home IoT through a lens of Ontological Braiding we might begin to imagine ways of embedding the concrete positionalities of 'other' people, places, things, and ideas, therefore making the unheard stakes of any design particular for each home.

\subsection{Care Condition: Commitment and Reciprocity}

This theme is about instances where care emerged as a condition of interdependence rather than out of an obligation or imperative. Appreciating the quality of conditional interdependence is fundamental to feminist care ethics. As Puig de la Bellacasa emphasizes, "interdependence is not a contract, nor a moral ideal-it is a condition. Care is therefore concomitant to the continuation of life for many living beings in more than human entanglements" [9:10]. In this section we share some of the ways this condition manifested when enacting thingcare.

5.4.1 Slowness. Throughout this study, Browne and Key focused on documenting individual encounters with care. However, care can and does operate on timescales which span lifetimes. Care can be slow, intermittent, and even in those moments of in-betweenness, care is present-not as an obligatory response, but as a tacit commitment. At some point, Key started referring to Browne as the "Queen of Patience" because of the multitude of projects she has that involve lots of waiting. We have already mentioned her $20+$ year chair project, the orange peel fire starters that need months to dry in the sun, and the adorned birds' nests which require years to dry before material can be added, but there are many more, all of which (according to Key) "exist on a timescale that we don't often think about." On these occasions, care didn't stop when the nest went into the box or the orange peel bundle went into the conservatory, and Browne's motivation for this commitment was not only necessity, more importantly it had become a part of her identity-she was the Queen.

In a very different context, Key also participated in a longterm commitment to care-one that spanned generations. After her grandfather's passing, Key chose three items of his to keep, none of them sentimental per se-a hammer, a vice, and " $a$ big hunk of iron with a handle." The iron had primarily been used as a decorative door stopper, but a sudden need to iron after having just moved prompted her to clean and use it as intended. Scrubbing off the bits of rust and built-up dirt gave her an opportunity to reflect on the cumulative effects of the many caring hands this iron might have seen, saying, "He [Grandfather] used it, touched it, maintained it. That felt like a nice way to add to its history. Its history is clearly long but only tiny specks are revealed." Up to that point, Key had not actively thought about the ways she was contributing to the iron's history through a lineage of care or about how her care was enabled by the care of countless unknowable others.

5.4.2 Cost. Care is never without cost. And because of the commitments Browne and Key have to care, they and their things are bound together in reciprocity-for labor, time, attention, resources, etc. One way Browne and Key confronted this is through the occasionally destructive effects of their caring actions-where caring simultaneously meant destroying. For example, Browne has an antique sewing machine table which sits in her garden as a plant 


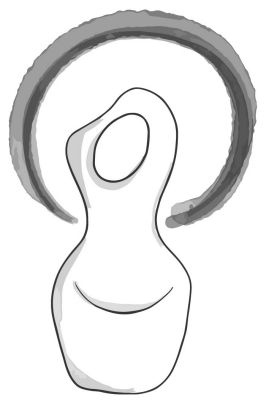

66 We thank ourselves for these flows and fluctuations of breath and data and knowing and not knowing. 99

Figure 6: Meditative Hub image and quote from the audio vignette

stand and sculpture that she recently repainted to protect from further rust and damage by the rain and moss. However, she was not entirely happy with the result because the worn authentic esthetic had been covered up by the new coat of paint. Her reflection on this act of preservation and care spoke to multiple exchanges, saying, "the cost of caring is emotional, it's physical and it can be destructive." Although she recognized the labor it took to clean and paint the machine, and the pain of feeling like she had done it a disservice, she also reasoned, "but do you know what? I'm not even looking at it anymore, in a way. It's up the top of the garden, and we sometimes sit out, and it does annoy me, but it'll get back to what it was like before. It'll be fine." Although the circumstances resemble Key's experience with the driftwood, Browne's reaction was quite different. In her response, we see how care's conditional quality meant that Browne had to accept the consequences and embrace the comfort of eventual timeworn erosion for her own well-being.

In addition to instances where selfcare and thingcare we linked as reciprocal costs to one another, Browne and Key also encountered instances where caring for someone else necessitated caring for a thing, and vice versa. In one occurrence, Key described this linkage after finding mold growing on a set of Winnie the Pooh baby books passed down by her mother-in-law. When the books were gifted at her baby shower, her mother-in-law took care to explain how they were a beloved toy and showed the tattered corners where Key's partner had teethed as a child. Key explained, "sometimes care for a thing is care for a person. I don't know that it's [the books] that sentimental for my partner but what we-I-am preserving is the sentiment for their mother." Even though Key didn't feel attached to the books, and she was unsure if her partner did either, she was bound to care for the fragile things because they were materially and emotionally enmeshed in her familial relationships.

In the examples above we get a sense of how care was an enduring commitment rather than a fleeting concern in that its motivation stemmed from a realization of identity, honoring history, or selfcare. Furthermore, they illustrate how framing care as a conditional relationship quality exposes its reciprocal costs.

5.4.3 Speculative Concept: Meditative Hub. Our last speculative concept, the Meditative Hub (Fig. 6) is a smart home hub devoted to harmony in the house... whether the home dwellers like it or not. When one of the house's smart devices needs a system update, it puts the whole house into "meditative mode," lowering lights and music, shutting off media, and leading a mindfulness session to guide the home towards collective regeneration and renewal although this might not always be at the most convenient time. Unlike most smart hubs, this one isn't always available or assistive. Its commitment to caring for the whole home have costs which are made clear upfront.

In reacting to this concept, Browne expressed an implicit association between the service Meditative Hub offers and traditional ideas of homely woman's work when saying, "as the Hub says, whether it is liked or not, whether at the right time or not, the Home Front needs the feminine touch. This means there is an instinct to keeping harmony which is to see and know when regeneration renewal and systems updates are needed and then TO DO IT!" Browne's comment illustrates "the normative assumptions baked into care: it is both essential for social reproduction and yet often invisible or undervalued" [40:7]. In this case, the necessity that a female (or anyone) commits to care work without accounting for the labor of both seeing and doing that work, as well as any backlash from those upon whom it is imposed (i.e., whether it is liked or not).

Whereas Browne's comment reminds us of what value might be overlooked through normative assumptions, other participants were inspired to find new or overlooked values through reexamining their everyday things. Francis, for example, reflected on how this might shift focus away from human relationships and "might remind myself the importance of the things that surround me." Similarly, Amelia mused, "it is interesting to think about the way we use 'stuff' for our own ends, and don't consider that it has a value itself-it is quite a fun idea to think that maybe objects also need to close down and meditate too!"

5.4.4 Implications for IoT: Or How Can Home IoT be More Like Chewed-Up Baby Books? A foundational notion in care ethics is that reciprocity is not necessarily symmetrical but rather complimentary [11]; it is informed by difference and interdependence which foster feelings of responsibility (i.e., interdependence) rather than fairness (i.e., justice). In the words of care ethicist Virginia Held, "their characteristic stance is neither egoistic nor altruistic. . but the wellbeing of a caring relation involves the cooperative well-being of those in the relation and the well-being of the relation itself" [39:23]. In this section we highlight the sometimes unexpected, intermittent, asymmetrical, yet always interlocking costs and commitments of thingcare. How might we reimagine home IoT if designers likewise take into consideration the concrete differences and capacities for reciprocal care? Would our designs start to better resist and confront the implicit and often discriminatory or marginalizing labor they require?

Dominant visions of home IoT make it difficult to see what potential for reciprocal care exists [7], which in turn limits modes of caring and obfuscates linkages like thingcare and selfcare (as seen in the example of Browne's sewing machine). But looking at the experience Key had with her Winnie the Pooh books we find inspiration for a different future vision. In that example, Key consciously labored to care for the books not out of ego or altruism but because they held the capacity to provide care to her in the form of strengthening and preserving familial bonds. Key did not 
act because they (all books, all things, or all gifts from her motherin-law) deserve care, have a right to care, or are entitled to care. Rather, she was both in a position to provide care and could experience concretely how they had been cherished in the past (they are dated the year her partner was born, the handwritten inscription inside tells the story of their gifting, the yellowing tape tells how they were preserved, the chew marks show their dynamic uses, etc.). It felt easy for Key to commit openly to laboring to preserve these books and accept the reciprocal costs in their asymmetry because some of the particular stakes were made clear. By designing home IoT with a perspective of Care Condition we might find that practices of preservation and care change if home IoT was better equipped to offer particular, concrete, and complimentary care.

\section{DISCUSSION}

The goal of this paper is not to advise on how to make users care more or less about any given technology; rather, it is to suggest a framing perspective from which to attend to the specific ways that care is and might be enacted so that we might move towards further defining and realizing equitable and responsible approaches to home IoT. Through a care perspective's privileging of relational axes such as embodiment (e.g., Browne's orange peel fire starter ritual), positionality (e.g., Key's reflection on ownership during her rainy walk through the park), temporality (e.g., Browne reflecting on the unimportance of finishing her $20+$ year chair project), or reciprocity (e.g. Key practicing family-care through thingcare when restoring some baby books) we appreciate that in order to realize those equitable and responsible approaches we need a different relationship to IoT, not just different devices. And because a care perspective does not shy away from friction-it stays with the trouble [38] it resists solutionism, not as a stable heuristic but a context driven, and relational tool for both "doing and noticing, not necessarily in that order." In the next section we highlight a few examples of where we saw such relational trouble in this work and expand on what implications we see for design and $\mathrm{HCI}$ in engaging those relations.

\subsection{Frictions with Power}

As we have argued, care is happening-and not in a vacuum. Practices of care are inevitably constructed on top of power differentials between subjects (humans, animals, artifacts, environments, etc.). Therefore, "a critical practice of care would insist on paying attention to the privileged position of the caring subject, wary of who has the power to care, and who or what tends to get designated the proper or improper objects of care." [56:636]. We were forced to grapple with dimensions of these positions when exploring design implications of a care perspective in our speculative sketches. For example, when Browne likened Care4Tech to a museum with the power to decide what was worthy of care and how that care should be enactedsignifying how care can elevate or reduce views of deservedness, or when Terry felt put-off by the Sensitive Snuggler's privileged 'everybody cares about me' attitude. Differentials like these are baked into design decisions such as what a home IoT will care about and what it will not, or for whom/what it will be optimized, and whom/what will be excluded. In the case of planned (or willfully unplanned) obsolescence, these power relations manifest in how and what care home IoT will afford, and in what ways they will resist modes of care. A key feminist strategy aligned to care ethics is to "investigate and even nurture the marginal, for here alternatives to normalizing discourses are often most visible" [8:1305]. For example, if asking who/what a home IoT is optimized for, we wonder what that might look like with 'home' at the center-might we have domestic stewards instead of domestic assistants? Or, in exploring what an IoT might care about, we might foreground ecologies of objects as constructs of home-would we invite the Roomba to the still life and appreciate its shimmer? A practice of care in domestic IoT, then, is paying attention to embedded positions of power and in finding ways to nurture those ignored as a means to both disrupt normative conventions as well as to explore alternative possibilities for IoT [8].

\subsection{Frictions with Privilege}

Enactments of care are, in effect, a double privilege. Firstly, in the power to care, and secondly in the privilege to be cared for. However, the cost can have a triple effect because for every privileged care giver and receiver there are countless others excluded altogether. Again, this is not to say that we are all entitled to care, but simply to state that care is a choice, and in that choice there are consequences, some of which are seen and some which are unseen. We saw this play out when Browne alluded to the backlash from receivers of care when reacting to the speculative concept Mediative Hub who puts the entire house in 'meditative mode' "whether the home dwellers like it or not." In this example the receivers of care were rendered powerless, leading to possible feelings of indebtedness, and no assurance of their ability to reciprocate. The caregiver, in this case, is exposed to any negative effects of those reactions, and lastly there are those who were left out of the equation entirely. To this last point, we invoke STS scholar Aryn Martin's assertion that "care is a selective mode of attention: it circumscribes and cherishes some things, lives, or phenomena as its objects. In the process, it excludes others" [56:637]. Within domestic IoT discourses, finite and selective attention are not new concerns (e.g., Weiser's 'calm technology' of the early 90's [87]). More recent responses to this 'problem of human fallibility' are to design along the Interaction-Attention Continuum [5], again with the goal of seamless integration and the potential for interaction at any moment. These ideals are embodied, for example, in home hubs which are continuously available to give and receive attention. In this vision there is no space on the continuum reserved for inattention as a means of care, nor is there an account of the cost when attention to some is privileged over others. Educing feminist assertions such as "to or not to care about/for something/somebody, inevitably does and undoes relation" [10:70], this leaves us to contemplate what that signals about the forgotten others, how can we shed light on those undone relations, and question how we can make concrete, and so practice, care for these others when the cost of their exclusion is diverted or hidden. Again, if we use a care perspective to shine a light in the margins of home IoT and cast a shadow out into the future we might discover ways to embrace non-normative attunements that invite rather than close off non-deterministic modes of engagement-would we come home to find gold thread, hair, or grasses woven into our Wi-Fi routers? 


\section{CONCLUSION}

In this paper we leveraged care theory to attend to the entanglements and observations from an auto-dialogical RtD study on caring for things at home. We presented four emergent themes on relationships to thingcare at home: Care Spectacle, Care Liminality, Ontological Braiding, and Care Condition. These themes were collaboratively developed into four speculative IoT concepts to further surface implications for home IoT such as designing for embodiment, positionality, temporality, and reciprocity. Finally, we discussed how spaces of friction within care practices, such as power differentials, positions of privilege, and processes of exclusion might serve design and HCI communities in critical new imaginaries for home IoT.

We wish to conclude by stating that although this body of work serves to partially showcase how the critical and generative capacity of this approach lies precisely in its relational stance, there are limitations of using care ethics as a lens for future home IoT design. In her reading of Benhabib, Bardzell articulates one theoretically extreme limitation: "lacking any appeal to the universal, it [care ethics] can't ever transcend out of micro-situations or be able to ethically distinguish between two micro-situations to say one is better than the other" [11:770]. In the case of most practical applications this might not feel pressing, however it exposes two of the biggest hurdles to applying care ethics in actual design thinking for home IoT: one, designers will need to know and be transparent about what universal values they are working off of and working towards, and two, invest in mechanisms to actually listen to the voices of 'concrete others' in those situations. These are crucial for identifying and actively working to deconstruct normative views of domesticity and domestic computing for productive reimagining. And because, as Bardzell also reminds us, "the moral commitments we make have deep implications for the design of our future society" [7:765] we need more ethical framing for how to design and evaluate even if they are flawed, difficult, or what Deschamps-Sonsino calls "at the very edge of what is monetizable" [22].

Although this work was itself an analysis and design journey of micro-situations, we took care to extract higher level themes and real-world implications that might inform action now and in the future. We urge designers and researchers to use care as a perspective to tend to the specificity of their own contexts, practices, temporalities, and stakeholders, but also to transcend and abstract them in an effort to trouble the forces of power, knowledge, and labor which too often go unseen, unvalued, and uncared for. In the words of Aryn Martin, we need to dedicate ourselves to "remaining critical and attentive to the situated workings of care in the world" [56:627].

\section{ACKNOWLEDGMENTS}

We thank our participants for their generosity, warmth and adaptiveness during uncertain times. We also thank Audrey Desjardins, Heidi Biggs, John Vines, and Jens Alexander Ewald for their thoughtful editorial feedback. This project has received funding from the European Union's Horizon 2020 research and innovation programme under the Marie Skłodowska-Curie grant agreement No 813508.

\section{REFERENCES}

[1] Ryan Aipperspach, Ben Hooker, and Allison Woodruff. 2008. The heterogeneous home. In Proceedings of the 10th international conference on Ubiquitous computing
- UbiComp '08, 222. https://doi.org/10.1145/1409635.1409666

[2] Yoko Akama, Ann Light, and Takahito Kamihira. 2020. Expanding Participation to Design with More-Than-Human Concerns. In Proceedings of the 16th Participatory Design Conference 2020 - Participation(s) Otherwise - Volume 1, 1-11. https://doi. org/10.1145/3385010.3385016

[3] Morgan G Ames, Janet Go, Joseph'Jofish' Kaye, and Mirjana Spasojevic. 2010. Making love in the network closet: the benefits and work of family videochat. 145-154.

[4] James Auger. 2013. Speculative design: crafting the speculation. Digital Creativity 24, 1: 11-35. https://doi.org/10.1080/14626268.2013.767276

[5] Saskia Bakker and Karin Niemantsverdriet. 2016. The Interaction-Attention Continuum: Considering Various Levels of Human Attention in Interaction Design. International Journal of Design 10, 2: 15.

[6] Madeline Balaam, Rob Comber, Rachel E. Clarke, Charles Windlin, Anna Ståhl, Kristina Höök, and Geraldine Fitzpatrick. 2019. Emotion Work in ExperienceCentered Design. In Proceedings of the 2019 CHI Conference on Human Factors in Computing Systems - CHI '19, 1-12. https://doi.org/10.1145/3290605.3300832

[7] Jeffrey Bardzell, Shaowen Bardzell, and Mark A Blythe. 2018. Critical theory and interaction design. MIT Press.

[8] Shaowen Bardzell. 2010. Feminist HCI: Taking Stock and Outlining an Agenda for Design. In Proceedings of the SIGCHI Conference on Human Factors in Computing Systems (CHI '10), 1301-1310. https://doi.org/10.1145/1753326.1753521

[9] Maria Puig de la Bellacasa. 2011. Matters of care in technoscience: Assembling neglected things. Social Studies of Science 41, 1: 85-106. https://doi.org/10.1177/ 0306312710380301

[10] Maria Puig de la Bellacasa. 2017. Matters of care: Speculative ethics in more than human worlds. U of Minnesota Press. Retrieved from www.jstor.org/stable/10.5749/j.ctt1mmfspt

[11] Seyla Benhabib. 1992. Situating the self: Gender, community, and postmodernism in contemporary ethics. Psychology Press.

[12] Jane Bennett. 2009. Vibrant Matter: A Political Ecology of Things. Duke University Press. https://doi.org/10.1215/9780822391623

[13] Barry Brown, Alex S Taylor, Shahram Izadi, Abigail Sellen, Joseph Jofish'Kaye, and Rachel Eardley. 2007. Locating family values: A field trial of the Whereabouts Clock. 354-371.

[14] Wen-Wei Chang, Elisa Giaccardi, Lin-Lin Chen, and Rung-Huei Liang. 2017. "Interview with Things": A First-thing Perspective to Understand the Scooter's Everyday Socio-material Network in Taiwan. In Proceedings of the 2017 Conference on Designing Interactive Systems - DIS '17, 1001-1012. https://doi.org/10.1145/ 3064663.3064717

[15] David Chatting, Paulina Yurman, David P. Green, Jo-Anne Bichard, and David S. Kirk. 2017. Ritual Machine V: Where are You? https://doi.org/10.6084/m9.figshare. 4746958.v1

[16] Marshini Chetty, Ja-Young Sung, and Rebecca E. Grinter. 2007. How Smart Homes Learn: The Evolution of the Networked Home and Household. In UbiComp 2007: Ubiquitous Computing, John Krumm, Gregory D. Abowd, Aruna Seneviratne and Thomas Strang (eds.). Springer Berlin Heidelberg, 127-144. Retrieved February 15, 2014 from http://link.springer.com.proxy.lib.sfu.ca/chapter/10.1007/978-3-54074853-3_8

[17] Marika Cifor and Patricia Garcia. 2020. Gendered by Design: A Duoethnographic Study of Personal Fitness Tracking Systems. ACM Transactions on Social Computing 2, 4: 1-22. https://doi.org/10.1145/3364685

[18] Andy Crabtree and Tom Rodden. 2004. Domestic Routines and Design for the Home. Computer Supported Cooperative Work (CSCW) 13, 2: 191-220. https://doi. org/10.1023/B:COSU.0000045712.26840.a4

[19] Andy Crabtree and Peter Tolmie. 2016. A Day in the Life of Things in the Home. In Proceedings of the 19th ACM Conference on Computer-Supported Cooperative Work \& Social Computing - CSCW'16, 1736-1748. https://doi.org/10.1145/2818048. 2819954

[20] Deane Curtin. 1991. Toward an ecological ethic of care. Hypatia 6, 1: 60-74.

[21] Dries De Roeck, Karin Slegers, Johan Criel, Marc Godon, Laurence Claeys, Katriina Kilpi, and An Jacobs. 2012. I Would DiYSE for It!: A Manifesto for Do-ityourself Internet-of-things Creation. In Proceedings of the 7th Nordic Conference on Human-Computer Interaction: Making Sense Through Design (NordiCHI '12), 170-179. https://doi.org/10.1145/2399016.2399044

[22] Alexandra Deschamps-Sonsino. 2020. Don't Press Snooze: Design in a Crisis. Branch. Retrieved from https://branch-staging.climateaction.tech/2020/10/15/ dont-press-snooze-design-in-a-crisis/

[23] Audrey Desjardins, Heidi R. Biggs, Cayla Key, and Jeremy E. Viny. 2020. IoT Data in the Home: Observing Entanglements and Drawing New Encounters. In Proceedings of the 2020 CHI Conference on Human Factors in Computing Systems, 1-13. https://doi.org/10.1145/3313831.3376342

[24] Audrey Desjardins, Cayla Key, Heidi Briggs, and Kelsey Aschenbeck. 2019. Bespoke Booklets: A Method for Situated Co-Speculation. In Proc. DIS'19, New York, ACM Press.

[25] Audrey Desjardins, Jeremy E. Viny, Cayla Key, and Nouela Johnston. 2019. Alternative Avenues for IoT: Designing with Non-Stereotypical Homes. In Proceedings 
of the 2019 CHI Conference on Human Factors in Computing Systems - CHI '19, 1-13. https://doi.org/10.1145/3290605.3300581

[26] Josephine Donovan and Carol J Adams. 1996. Beyond animal rights: A feminist caring ethic for the treatment of animals.

[27] Abigail Durrant, Alex Taylor, David Frohlich, Abigail Sellen, and David Uzzell 2009. Photo displays and intergenerational relationships in the family home.

[28] Arturo Escobar. 2018. Designs for the pluriverse: Radical interdependence, autonomy and the making of worlds. Duke University Press.

[29] Berenice Fisher and Joan Tronto. 1990. Toward a feminist theory of caring. Circles of care: Work and identity in women's lives: 35-62.

[30] Sarah Elizabeth Fox. 2018. Maintaining the Menstruating Body: Feminist Interventions on Care Resources.

[31] Sarah Fox and Daniela K. Rosner. 2016. Continuing the Dialogue: Bringing Research Accounts Back into the Field. In Proceedings of the 2016 CHI Conference on Human Factors in Computing Systems (CHI '16), 1426-1430. https: //doi.org/10.1145/2858036.2858054

[32] Ester Fritsch, Irina Shklovski, and Rachel Douglas-Jones. 2018. Calling for a revolution: An analysis of IoT manifestos. 1-13.

[33] Bill Gaver, Tony Dunne, and Elena Pacenti. 1999. Design: Cultural probes. interactions 6, 1: 21-29. https://doi.org/10.1145/291224.291235

[34] William Gaver. 2011. Making spaces: how design workbooks work. 1551. https: //doi.org/10.1145/1978942.1979169

[35] Carol Gilligan. 1993. In a different voice: psychological theory and women's development. Harvard University Press, Cambridge, Mass.

[36] Lars Hallnäs and Johan Redström. 2001. Slow Technology - Designing for Reflection. Personal and Ubiquitous Computing 5, 3: 201-212. https://doi.org/10.1007/ PL00000019

[37] Donna Haraway. 1988. Situated Knowledges: The Science Question in Feminism and the Privilege of Partial Perspective. Feminist Studies 14, 3: 575-599. https: //doi.org/10.2307/3178066

[38] Donna J Haraway. 2016. Staying with the trouble: Making kin in the Chthulucene Duke University Press.

[39] Virginia Held. 2006. The ethics of care: personal, political, and global. Oxford University Press, Oxford; New York.

[40] Hi' ilei Julia Kawehipuaakahaopulani Hobart and Tamara Kneese. 2020. Radical Care: Survival Strategies for Uncertain Times. Social Text 38, 1 (142): 1-16. https: //doi.org/10.1215/01642472-7971067

[41] Lara Houston, Steven J. Jackson, Daniela K. Rosner, Syed Ishtiaque Ahmed, Meg Young, and Laewoo Kang. 2016. Values in Repair. In Proceedings of the 2016 CHI Conference on Human Factors in Computing Systems - CHI '16, 1403-1414. https://doi.org/10.1145/2858036.2858470

[42] Dorothy Howard and Lilly Irani. 2019. Ways of Knowing When Research Subjects Care. In Proceedings of the 2019 CHI Conference on Human Factors in Computing Systems - CHI '19, 1-16. https://doi.org/10.1145/3290605.3300327

[43] Miwa Ikemiya and Daniela K. Rosner. 2014. Broken probes: toward the design of worn media. Personal and Ubiquitous Computing 18, 3: 671-683. https://doi.org/ 10.1007/s00779-013-0690-y

[44] Steven J. Jackson. 2014. Rethinking Repair. In Media Technologies, Tarleton Gillespie, Pablo J. Boczkowski and Kirsten A. Foot (eds.). The MIT Press, 221-240. https://doi.org/10.7551/mitpress/9780262525374.003.0011

[45] Steven J. Jackson and Laewoo Kang. 2014. Breakdown, obsolescence and reuse: $\mathrm{HCI}$ and the art of repair. In Proceedings of the SIGCHI Conference on Human Factors in Computing Systems, 449-458. https://doi.org/10.1145/2556288.2557332

[46] Tom Jenkins. 2018. Cohousing IoT: Design Prototyping for Community Life. In Proceedings of the Twelfth International Conference on Tangible, Embedded, and Embodied Interaction (TEI '18), 667-673. https://doi.org/10.1145/3173225.3173244

[47] Heekyoung Jung, Shaowen Bardzell, Eli Blevis, James Pierce, and Erik Stolterman 2011. Deep Narratives of Ensoulment and Heirloom Status. 13.

[48] Cayla Key and Audrey Desjardins. 2019. Rep(Air): An Olfactory Interface For Bike Maintenance and Care. In Proc. of the 4th Biennial Research Through Design Conference. https://doi.org/10.6084/m9.figshare.7855769.v3

[49] Vera Khovanskaya and Phoebe Sengers. 2019. Data Rhetoric and Uneasy Alliances: Data Advocacy in US Labor History. In Proceedings of the 2019 on Designing Interactive Systems Conference - DIS '19, 1391-1403. https://doi.org/10.1145/3322276. 3323691

[50] David S. Kirk and Abigail Sellen. 2010. On human remains: Values and practice in the home archiving of cherished objects. ACM Transactions on Computer-Human Interaction 17, 3: 1-43. https://doi.org/10.1145/1806923.1806924

[51] Martine D Lappé. 2014. Taking care: Anticipation, extraction and the politics of temporality in autism science. BioSocieties 9, 3: 304-328.

[52] Solana Larsen. Mozilla, Internet Health Report *Privacy Included: Rethinking the smart home. 23.

[53] Ann Light and Yoko Akama. 2014. Structuring future social relations: the politics of care in participatory practice. In Proceedings of the 13th Participatory Design Conference on Research Papers - PDC '14, 151-160. https://doi.org/10.1145/2661435. 2661438

[54] Leah Maestri and Ron Wakkary. 2011. Understanding repair as a creative process of everyday design. In Proceedings of the 8th ACM conference on Creativity and cognition (C\&C '11), 81-90. https://doi.org/10.1145/2069618.2069633

[55] Ezio Manzini. 2015. Design, when everybody designs: An introduction to design for social innovation. MIT press.

[56] Aryn Martin, Natasha Myers, and Ana Viseu. 2015. The politics of care in technoscience. Social Studies of Science 45, 5: 625-641. https://doi.org/10.1177/ 0306312715602073

[57] Shannon Mattern. 2018. Maintenance and care. Places fournal.

[58] Shannon Mattern. 2018. Maintenance and Care. Places fournal. https://doi.org/10. $22269 / 181120$

[59] Annemarie Mol, Ingunn Moser, and Jeannette Pols. 2015. Care in Practice: On Tinkering in Clinics, Homes and Farms. Retrieved November 24, 2020 from https: //doi.org/10.14361/transcript.9783839414477

[60] Michelle Murphy. 2015. Unsettling care: Troubling transnational itineraries of care in feminist health practices. Social Studies of Science 45, 5: 717-737.

[61] Carman Neustaedter. 2012. Autobiographical Design in HCI Research: Designing and Learning through Use-It-Yourself. 10.

[62] Nel Noddings. 2013. Caring: a relational approach to ethics \& moral education. Univ. of Calif. Press, Berkeley, Calif.

[63] William Odom, Richard Banks, David Kirk, Richard Harper, Siân Lindley, and Abigail Sellen. 2012. Technology heirlooms?: considerations for passing down and inheriting digital materials. 337. https://doi.org/10.1145/2207676.2207723

[64] William Odom, Ron Wakkary, Jeroen Hol, Bram Naus, Pepijn Verburg, Tal Amram, and Amy Yo Sue Chen. 2019. Investigating Slowness as a Frame to Design LongerTerm Experiences with Personal Data: A Field Study of Olly. In Proceedings of the 2019 CHI Conference on Human Factors in Computing Systems, 1-16. https: //doi.org/10.1145/3290605.3300264

[65] William Odom, John Zimmerman, and Jodi Forlizzi. 2010. Designing for Dynamic Family Structures: Divorced Families and Interactive Systems. In Proceedings of the 8th ACM Conference on Designing Interactive Systems (DIS '10), 151-160. https://doi.org/10.1145/1858171.1858199

[66] Doenja Oogjes, William Odom, and Pete Fung. 2018. Designing for an Other Home: Expanding and Speculating on Different Forms of Domestic Life. In Proceedings of the 2018 Designing Interactive Systems Conference (DIS '18), 313-326. https://doi.org/10.1145/3196709.3196810

[67] Kari Paul. 2019. Amazon's doorbell camera Ring is working with police - and controlling what they say. The Guardian. Retrieved from https://www.theguardian.com/technology/2019/aug/29/ring-amazon-policepartnership-social-media-neighbor

[68] Daniela K. Rosner and Morgan Ames. 2014. Designing for Repair?: Infrastructures and Materialities of Breakdown. In Proceedings of the 17th ACM Conference on Computer Supported Cooperative Work \& Social Computing (CSCW '14), 319-331. https://doi.org/10.1145/2531602.2531692

[69] Daniela K. Rosner and Morgan Ames. 2014. Designing for repair?: infrastructures and materialities of breakdown. 319-331. https://doi.org/10.1145/2531602.2531692

[70] Daniela K. Rosner, Miwa Ikemiya, Diana Kim, and Kristin Koch. 2013. Designing with traces. In Proceedings of the SIGCHI Conference on Human Factors in Computing Systems - CHI '13, 1649. https://doi.org/10.1145/2470654.2466218

[71] Daniela K. Rosner, Miwa Ikemiya, Diana Kim, and Kristin Koch. 2013. Designing with traces. In Proceedings of the SIGCHI Conference on Human Factors in Computing Systems - CHI '13, 1649. https://doi.org/10.1145/2470654.2466218

[72] Daniela K. Rosner and Fred Turner. 2015. Theaters of Alternative Industry: Hobbyist Repair Collectives and the Legacy of the 1960s American Counterculture. In Design Thinking Research, Hasso Plattner, Christoph Meinel and Larry Leifer (eds.). Springer International Publishing, 59-69. Retrieved August 4, 2015 from http://link.springer.com.proxy.lib.sfu.ca/chapter/10.1007/978-3-319-06823-7 5

[73] Zoë Sadokierski. 2019. Critical Journal / Contextual Portfolio: A framework for documenting and disseminating RtD as scholarly research. Figshare. https: //doi.org/10.6084/m9.figshare.7855829.v1

[74] Anne Salmond. 2014. Tears of Rangi: Water, power, and people in New Zealand. HAU: Journal of Ethnographic Theory 4, 3: 285-309. https://doi.org/10.14318/hau4. 3.017

[75] Elizabeth B.-N. Sanders and Pieter Jan Stappers. 2008. Co-creation and the new landscapes of design. CoDesign 4, 1: 5-18. https://doi.org/10.1080/ 15710880701875068

[76] Sarah Pink, Kerstin Mackley, Roxana Morosanu, Val Mitchell, and Tracy Bhamra. 2017. Making homes: ethnography and design. Bloomsbury Publishing.

[77] Richard D Sawyer and Joe Norris. 2013. Duoethnography. Oxford University Press.

[78] Laurel Swan, Alex S. Taylor, and Richard Harper. 2008. Making place for clutter and other ideas of home. ACM Transactions on Computer-Human Interaction 15, 2: 1-24. https://doi.org/10.1145/1375761.1375764

[79] Alex S. Taylor, Susan P. Wyche, and Joseph "Jofish" Kaye. 2008. Pottering by Design. In Proceedings of the 5th Nordic Conference on Human-computer Interaction: Building Bridges (NordiCHI '08), 363-372. https://doi.org/10.1145/1463160. 1463200

[80] Austin Toombs, Shaowen Bardzell, and Jeffrey Bardzell. 2017. The Proper Care and Feeding of Hackerspaces: Care Ethics and Cultures of Making. interactions 24, 3: 12-13. https://doi.org/10.1145/3068259 
[81] Austin Toombs, Shad Gross, Shaowen Bardzell, and Jeffrey Bardzell. 2017. From Empathy to Care: A Feminist Care Ethics Perspective on Long-Term ResearcherParticipant Relations. Interacting with Computers 29, 1: 45-57. https://doi.org/10 1093/iwc/iww010

[82] Joan C. Tronto. 1993. Moral boundaries: a political argument for an ethic of care. Routledge, New York.

[83] Vasiliki Tsaknaki and Ylva Fernaeus. 2016. Expanding on Wabi-Sabi as a Design Resource in HCI. 5970-5983. https://doi.org/10.1145/2858036.2858459

[84] Anna Lowenhaupt Tsing, Nils Bubandt, Elaine Gan, and Heather Anne Swanson. 2017. Arts of living on a damaged planet: Ghosts and monsters of the Anthropocene. $\mathrm{U}$ of Minnesota Press.

[85] Edward Tufte. 1973. The visual display of quantitative information.

[86] Ron Wakkary, Doenja Oogjes, Henry W. J. Lin, and Sabrina Hauser. 2018. Philosophers Living with the Tilting Bowl. In Proceedings of the 2018 CHI Conference on Human Factors in Computing Systems - CHI '18, 1-12. https://doi.org/10.1145/
3173574.3173668

[87] Mark Weiser and John Seely Brown. 1997. The coming age of calm technology. In Beyond Calculation. Springer, 75-85.

[88] Kristin Williams, Rajitha Pulivarthy, Scott E. Hudson, and Jessica Hammer. 2020. The Upcycled Home: Removing Barriers to Lightweight Modification of the Home's Everyday Objects. In Proceedings of the 2020 CHI Conference on Human Factors in Computing Systems, 1-13. https://doi.org/10.1145/3313831.3376314

[89] Allison Woodruff, Sally Augustin, and Brooke Foucault. 2007. Sabbath Day Home Automation: "It's Like Mixing Technology and Religion." In Proceedings of the SIGCHI Conference on Human Factors in Computing Systems (CHI '07), 527-536. https://doi.org/10.1145/1240624.1240710

[90] Alexandra Zafiroglu and Michele Chang. 2007. Digital homes on wheels: designing for the unimagined home. Personal and Ubiquitous Computing 11, 5: 395-402. https://doi.org/10.1007/s00779-006-0074-7 